\title{
Sex difference in clot lysability and association to coronary artery calcification
}

\author{
Ramshanker Ramanathan ${ }^{1,2,3,4^{*}}$ (D), Niels Peter R. Sand ${ }^{1,2}$, Johannes J. Sidelmann ${ }^{3,4}$, Bjarne L. Nørgaard ${ }^{5}$ \\ and Jørgen B. Gram ${ }^{3,4}$
}

\begin{abstract}
Background: Incidence and prevalence of cardiovascular disease (CVD) differ between sexes, and women experience CVD later than men. Changes in fibrin clot lysability are associated with CVD, and the present study addresses sex differences in fibrin clot lysability in asymptomatic middle-aged individuals and the relation to coronary artery calcification (CAC).

Methods: Participants free of morbidities and medication, $N=163$, were randomly chosen from a national registry among citizens, 50 or 60 years of age, and were followed for 5 years. CAC was determined by the Agatston (Ag) score both at baseline and at follow-up. Based on the changes in Ag, the population was divided into two groups: $\Delta \mathrm{Ag}=$ $0 \mathrm{U}$ or $\Delta \mathrm{Ag}>0 \mathrm{U}$. Fibrin clot analyses were based on turbidimetric methods.

Results: At baseline, 116 women and 97 men were included; 84 women and 79 men completed the 5-year follow-up (77\%). Independently of covariates, women with $\Delta \mathrm{Ag}>0$ had reduced mean (SD) fibrin lysability at follow-up, $40.2 \%$ (15.9), both in comparison to baseline, $47.8 \%$ (20.4), $p=0.001$, to women with $\Delta \mathrm{Ag}=0 \mathrm{U}, 51$. $2 \%(24.5), p=0.028$, and to men with $\Delta \mathrm{Ag}>0 \mathrm{U}, 54.4 \%(21.0), p=0.002$.

Conclusions: Fibrin clot lysability changes over time with considerable sex differences. Women with progression of CAC have reduced fibrin clot lysability compared to men, indicating a sex-specific association between morphological vessel wall changes and fibrin clot lysability.
\end{abstract}

Keywords: Sex difference, Cardiovascular disease, Coronary artery calcification, Fibrin clot lysability

\section{Background}

The incidence and prevalence of cardiovascular disease (CVD) differ between sexes, and women experience CVD later than men [1]. These epidemiological observations have been the fundament for studies searching for sex differences in biochemical [2] and morphological [3] characteristics in the subclinical phase of the disease.

The preponderance of studies have shown that premenopausal women have a favorable lipid profile, lower blood pressure levels, and less coronary artery calcification (CAC) compared with age-matched men $[4,5]$. After the menopause the condition changes towards alignment with the age-dependent changes observed in men [6], probably due

\footnotetext{
* Correspondence: ramshanker.ramanathan2@rsyd.dk

${ }^{1}$ Department of Cardiology, Hospital of South West Denmark, Esbjerg, Denmark

${ }^{2}$ Department of Regional Health Research, University of Southern Denmark,

Esbjerg, Denmark

Full list of author information is available at the end of the article
}

to the lack of the protecting effects of estrogens in postmenopausal women $[7,8]$. Studies have indicated that although the debut of CVD is postponed, the short-term mortality after myocardial infarction (MI) is higher in women younger than 75 years old than in age-matched men [9]. The causes of these findings are unclear [10], but fibrin may in this context play an important role, as it is a matrix for tissue repair and has been shown to contribute to plaque growth in a multitude of ways [11-13]. Therefore, it might be of relevance to explore alterations in fibrin clot lysability in relation to development of CAC as a surrogate marker of CVD.

More than two decades ago, Fatah et al. observed a connection between abnormal fibrin architecture in men with MI compared to healthy controls [14]. Since then, studies have elaborated the link between CVD and altered fibrin structure and clot lysability in different patient categories [15-19]. Most of these studies have shown that defect 
fibrin clot lysability is associated with the evolution of CVD [15, 17, 20, 21]. However, sex differences in fibrin clot lysability have not been thoroughly evaluated, and the relation to coronary atherosclerosis is still speculative.

Consequently, in the present cross-sectional cohort study, we examined sex differences and changes over time in fibrin clot lysability in asymptomatic middleaged individuals. Furthermore, we addressed the potential association between fibrin clot lysability and CAC.

\section{Methods}

\section{Study design and participants}

This cross-sectional cohort study with follow-up recruiting participants from the Danish Risk Score (DanRisk) study [22] was performed at four hospitals (Svendborg, Odense, Vejle, and Esbjerg) in Southern Denmark from 2009 to 2010. Study participants were randomly chosen from the Danish Central Person Registry among citizens born either in 1949 or 1959. The present study focuses on participants recruited from Esbjerg [23]. In brief, 458 participants were invited at baseline, of whom 329 (72\%) accepted the invitation. After exclusion of individuals with symptomatic CVD (angina, myocardial infarction, treatment with percutaneous coronary revascularization or coronary by-pass surgery), atrial fibrillation, stroke, peripheral artery disease, heart valve disease, and diabetes or taking any kind of medication, a total of $213(47 \%)$ comprised the study population at baseline. After 5 years, all 213 participants were re-invited to a follow-up assessment, and 163 (77\%) participants were re-examined and thus constituted the final population.

Prior to examination, the participants filled in a questionnaire concerning medical history, family history with CVD, and smoking habits. In addition, participants were interviewed about the same topics. Physical examination included BMI calculations based on measurements of height and weight, waist circumference, blood pressure and pulse (average of three measurements after 5 min of rest), and an ECG.

\section{Cardiac CT}

All CT scans both at baseline and at follow-up were analyzed by the same experienced cardiologist, who was blinded to all other patient data. CAC was expressed as Agatston (Ag) score [24]. The internal validity of the calcium scoring was high [22]. Non-contrast scan data were acquired during an inspiratory breath hold.

$\mathrm{Ag}$ at baseline was assessed by a Toshiba 64-slice CTscanner (Aquilion, Toshiba Medical Systems). The following technical settings were used: gantry rotation time $450 \mathrm{~ms}$, collimation $64 \times 0.5 \mathrm{~mm}$, slice thickness $3 \mathrm{~mm}$, $120 \mathrm{kV}$ tube voltage, $240 \mathrm{~mA}$ tube current, and prospective gating at $75 \%$ of the R-R interval. At follow-up, Ag was assessed using a Philips 64-slice scanner (Brilliance 64, Philips Healthcare). The following technical settings were used: gantry rotation time $400 \mathrm{~ms}$, collimation $64 \times$ $0.625 \mathrm{~mm}$, slice thickness $2.5 \mathrm{~mm}, 120 \mathrm{kV}$ tube voltage, $220 \mathrm{~mA}$ tube current, and prospective gating at $75 \%$ of the R-R interval. The mean (SD, range, $k$-factor) estimated radiation dose at baseline was $1.36 \mathrm{mSv}(0.54,0.49$ $3.06 \mathrm{mSv}, 0.0145)$, and the mean (SD, range, $k$-factor) estimated radiation dose at follow-up was $1.09 \mathrm{mSv}(0.31$, $0.48-2.22 \mathrm{mSv}, 0.0145)$.

The study population was separated into two groups based on the numeric difference between $\mathrm{Ag}$ at followup and baseline: $\Delta \mathrm{Ag}=0 \mathrm{U}$ or $\Delta \mathrm{Ag}>0 \mathrm{U}$.

\section{Blood collection and handling}

Blood samples were drawn from an antecubital vein into sterile vacuum plastic tubes containing either $0.109 \mathrm{~mol} / \mathrm{L}$ citrate or no anticoagulants, and the plasma or serum isolated after $20 \mathrm{~min}$ of centrifugation at $2000 \mathrm{~g}$ at $20^{\circ} \mathrm{C}$ were frozen and stored in aliquots at $-80^{\circ} \mathrm{C}$ until analysis.

\section{Biochemical analysis}

Lipids were analyzed using Cholesterol, Direct LDL, Ultra HDL, and Triglycerides kits employing the Architect C16000 analyzer. Kits and analyzer were from Abbott, Wiesbaden, Germany. Concentrations of CRP and fibrinogen were determined on a BN-II nephelometer using antibodies and reagents from Siemens Healthcare Diagnostics $\mathrm{GmbH}$, Marburg, Germany. Plasminogen activator inhibitor type 1 (PAI-1) antigen, was quantitatively determined by a sandwich enzyme immunoassay (ELISA) using in-house specific antibodies as previously described [25] employing a microplate reader (Tecan Trading AG, Basle, Switzerland).

Fibrin clot lysis was recorded using turbidity measurements as previously described [20]. In brief, citratestabilized plasma was mixed with thrombin, $\mathrm{CaCl}_{2}$, and Tween 80 and incubated overnight in a microtiter plate sealed with adhesive tape. All clots were made in duplicate. To initiate fibrinolysis, t-PA and flufenamic acid were added onto the clots. The 405-nm optical density (OD) was then followed on a Sunrise plate reader (Tecan Austria, Grödig/ Salzburg, Austria) every $5 \mathrm{~min}$ for $4 \mathrm{~h}$ at $25^{\circ} \mathrm{C}$. The rate of fibrinolysis per hour was determined from the slope of the curve at the time when the slope became constant and was normalized with respect to the maximum absorbency value before lysis initiation.

\section{Statistics}

Continuous variables are presented as means and standard deviations (SD) or median and interquartile ranges (IQR) as appropriate. Normality was examined by the ShapiroWilk test as well as by visually assessing histograms and Q-Q plots. If possible, non-normally distributed variables were $\log$-transformed to achieve normality. Dichotomous variables are shown as numbers and percentages. Student's $t$ test was used for comparison of normally distributed 
continuous variables and the Mann-Whitney test for comparison of non-normally distributed continuous variables. The $\chi^{2}$ test was performed for comparison of dichotomous variables. The paired Student's $t$ test was used for paired comparison of normally distributed continuous variables, and the Wilcoxon signed rank test was used for paired comparison of non-normally distributed continuous variables. $p$ values $<0.05$ were considered statistically significant. Covariates were identified as variables which were significantly different between the sexes in the univariate analyses and correlated with fibrin clot lysability using the Spearman correlation test. A linear regression model using fibrin clot lysability as the dependent variable was created, and the model was adjusted for identified covariates. To ensure model validation, Q-Q plots for residuals were inspected for normality. Stata 15.0, StataCorp, TX, USA, was used for statistical analyses.

\section{Results}

\section{Baseline and follow-up characteristics}

Participants were followed for a mean (range) of 5.5 years (5.2-5.7 years). At baseline, 116 women and 97 men were included and 84 women and 79 men completed the followup. Study population characteristics at baseline and followup are shown in Tables 1 and 2. Women had lower levels of systolic and diastolic blood pressures, lower levels of triglycerides, higher high-density lipoprotein (HDL) cholesterol levels, and lower Ag compared to men (all $p<0.05$ ) both at baseline and follow-up, while C-reactive protein (CRP) was comparable between men and women. Body mass index (BMI) was lower in women at baseline $(p=0.039)$ but comparable among men and women at follow-up, while fibrinogen was higher in women at baseline $(p=0.008)$ and comparable among men and women at follow-up. $\Delta \mathrm{Ag}$ was significantly lower in women than in men $(p=0.012) . \Delta \mathrm{Ag}$ $=0 \mathrm{U}$ was observed in 85 participants (53 women). $\Delta \mathrm{Ag}$ $>0 \mathrm{U}$ was observed in 78 participants (31 women); of these, 23 participants (10 women) had $\Delta \mathrm{Ag}=1-10 \mathrm{U}, 35$ participants (12 women) had $\Delta \mathrm{Ag}=11-100$, and 20 participants (9 women) had $\Delta \mathrm{Ag}>100 \mathrm{U}$. Negative $\Delta \mathrm{Ag}$ observed in eight participants was classified as $\Delta \mathrm{Ag}=0 \mathrm{U}$.

\section{Fibrin clot lysability}

Women with $\Delta \mathrm{Ag}>0 \mathrm{U}$ had reduced mean (SD) clot lysability at follow-up compared to baseline, 40.2\% (15.9) versus $47.8 \%$ (20.4) $(p=0.001)$ (Fig. 1). There was no difference in clot lysability between baseline and follow-up in women with $\Delta \mathrm{Ag}>0 \mathrm{U}$ or in men. As shown in Figs. 2 and 3, at follow-up, women with $\Delta \mathrm{Ag}>0 \mathrm{U}$ had reduced mean (SD) clot lysability, $40.2 \%$ (15.9), compared to men with $\Delta \mathrm{Ag}>0 \mathrm{U}$, $54.4 \%(21.0)(p=0.002)$, and compared to women with $\Delta \mathrm{Ag}=0 \mathrm{U}, 51.2 \%(24.5) \quad(p=0.028)$. No difference in fibrin clot lysability between men with $\Delta \mathrm{Ag}=0 \mathrm{U}$ and $\Delta \mathrm{Ag}>0 \mathrm{U}$ was observed. Only triglycerides $(r=-0.168, p=0.032)$, fibrinogen $(r=-0.444, p<0.001)$, and PAI-1 $(r=-0.223, p=0.004)$ correlated with fibrin clot lysability. Adjusting for the confounding effect of

Table 1 Study population characteristics at baseline

\begin{tabular}{|c|c|c|c|}
\hline Baseline, $N=163$ & Men $(n=79)$ & Women $(n=84)$ & $p$ value \\
\hline \multicolumn{4}{|l|}{ Born } \\
\hline $1949(n=70)$ & $30(43)$ & $40(57)$ & \\
\hline $1959(n=93)$ & $49(53)$ & $44(47)$ & 0.21 \\
\hline \multicolumn{4}{|l|}{ Tobacco use } \\
\hline Never $(n=77)$ & $35(45)$ & $42(55)$ & \\
\hline Prior/current $(n=86)$ & $44(51)$ & $42(49)$ & 0.53 \\
\hline $\begin{array}{l}\text { Systolic blood pressure, } \mathrm{mmHg} \\
\text { Diastolic blood pressure, } \mathrm{mmHg}\end{array}$ & $\begin{array}{l}140(15) \\
82(9)\end{array}$ & $\begin{array}{l}132(19) \\
78(9)\end{array}$ & $\begin{array}{l}0.007 \\
0.002\end{array}$ \\
\hline Body mass index, $\mathrm{kg} / \mathrm{m}^{2}$ & $27.4(3.6)$ & $26.1(4.6)$ & 0.039 \\
\hline Agatston score, U & $0(0-33)$ & $0(0-7)$ & 0.012 \\
\hline $\begin{array}{l}\text { Total cholesterol, mmol// } \\
\text { LDL cholesterol, mmol/l } \\
\text { HDL cholesterol, mmol/l } \\
\text { Triglycerides, } \mathrm{mmol} / /\end{array}$ & $\begin{array}{l}5.42(0.97) \\
3.34(0.82) \\
1.26(1.02-1.54) \\
1.47(0.80)\end{array}$ & $\begin{array}{l}5.54(1.07) \\
3.23(0.91) \\
1.52(1.35-1.85) \\
1.14(0.60)\end{array}$ & $\begin{array}{l}0.44 \\
0.39 \\
<0.001 \\
0.003\end{array}$ \\
\hline C-reactive protein, mg/l & $0.74(0.36-1.61)$ & $0.72(0.29-1.86)$ & 0.67 \\
\hline Fibrinogen, $\mu \mathrm{mol} / \mathrm{l}$ & $8.9(7.9-9.9)$ & $9.6(8.5-10.9)$ & 0.008 \\
\hline $\mathrm{PAl}-1, \mathrm{ng} / \mathrm{ml}$ & $16.5(11.2-24.4)$ & $12.5(6.7-20.2)$ & 0.016 \\
\hline Fibrin clot lysability, \% & $54.8(19.7)$ & $51.5(22.2)$ & 0.32 \\
\hline
\end{tabular}

Values are presented as mean (SD), median (IQR), or number (\%). Information on C-reactive protein is missing on three participants. Information on PAI-1 is missing on four participants

LDL low-density lipoprotein, HDL high-density lipoprotein, PAl-1 plasminogen activator inhibitor type 1 
Table 2 Study population characteristics at follow-up

\begin{tabular}{|c|c|c|c|}
\hline Follow-up, $N=163$ & Men $(n=79)$ & Women $(n=84)$ & $p$ value \\
\hline \multicolumn{4}{|l|}{ Born } \\
\hline $1949(n=70)$ & $30(43)$ & $40(57)$ & \\
\hline $1959(n=93)$ & $49(53)$ & $44(47)$ & 0.21 \\
\hline \multicolumn{4}{|l|}{ Tobacco use } \\
\hline Never $(n=76)$ & $34(45)$ & $42(55)$ & \\
\hline Prior/current $(n=87)$ & $45(52)$ & $42(48)$ & 0.47 \\
\hline $\begin{array}{l}\text { Systolic blood pressure, } \mathrm{mmHg} \\
\text { Diastolic blood pressure, } \mathrm{mmHg}\end{array}$ & $\begin{array}{l}140(17) \\
81(8)\end{array}$ & $\begin{array}{l}133(16) \\
72(9)\end{array}$ & $\begin{array}{l}0.013 \\
<0.001\end{array}$ \\
\hline Body mass index, $\mathrm{kg} / \mathrm{m}^{2}$ & $28.1(4.2)$ & $26.9(4.7)$ & 0.063 \\
\hline Agatston score, U & $9(0-115)$ & $0(0-26)$ & 0.002 \\
\hline$\Delta$ Agatston score, $U$ & $4(0-49)$ & $0(0-10)$ & 0.012 \\
\hline $\begin{array}{l}\text { Total cholesterol, mmol/l } \\
\text { LDL cholesterol, mmol/l } \\
\text { HDL cholesterol, mmol/l } \\
\text { Triglycerides, mmol/I }\end{array}$ & $\begin{array}{l}5.31(0.85) \\
3.33(0.80) \\
1.30(1.10-1.40) \\
1.82(0.97)\end{array}$ & $\begin{array}{l}5.54(0.92) \\
3.30(0.93) \\
1.55(1.40-1.75) \\
1.50(0.89)\end{array}$ & $\begin{array}{l}0.10 \\
0.80 \\
<0.001 \\
0.032\end{array}$ \\
\hline C-reactive protein, mg/l & $0.74(0.46-1.61)$ & $0.70(0.30-2.18)$ & 0.74 \\
\hline Fibrinogen, $\mu \mathrm{mol} / \mathrm{l}$ & $8.9(7.7-10.3)$ & $9.5(8.4-11.1)$ & 0.056 \\
\hline $\mathrm{PAl}-1, \mathrm{ng} / \mathrm{ml}$ & $21.7(15.4-27.5)$ & $20.1(15.0-30.3)$ & 0.69 \\
\hline Fibrin clot lysability, \% & $52.1(20.5)$ & $47.2(22.3)$ & 0.14 \\
\hline
\end{tabular}

Values are presented as mean (SD), median (IQR), or number (\%). Information on Agatston score is missing on one participant $L D L$ low-density lipoprotein, $H D L$ high-density lipoprotein, $P A I-1$ plasminogen activator inhibitor type 1

fibrinogen, triglycerides, and PAI-1 showed that the observed reduced fibrin clot lysability in women with $\Delta \mathrm{Ag}>0 \mathrm{U}$ compared to women with $\Delta \mathrm{Ag}=0 \mathrm{U}$ and men with $\Delta \mathrm{Ag}>0 \mathrm{U}$ was independent of covariation $(p=0.028$ and $p=0.013$, respectively).

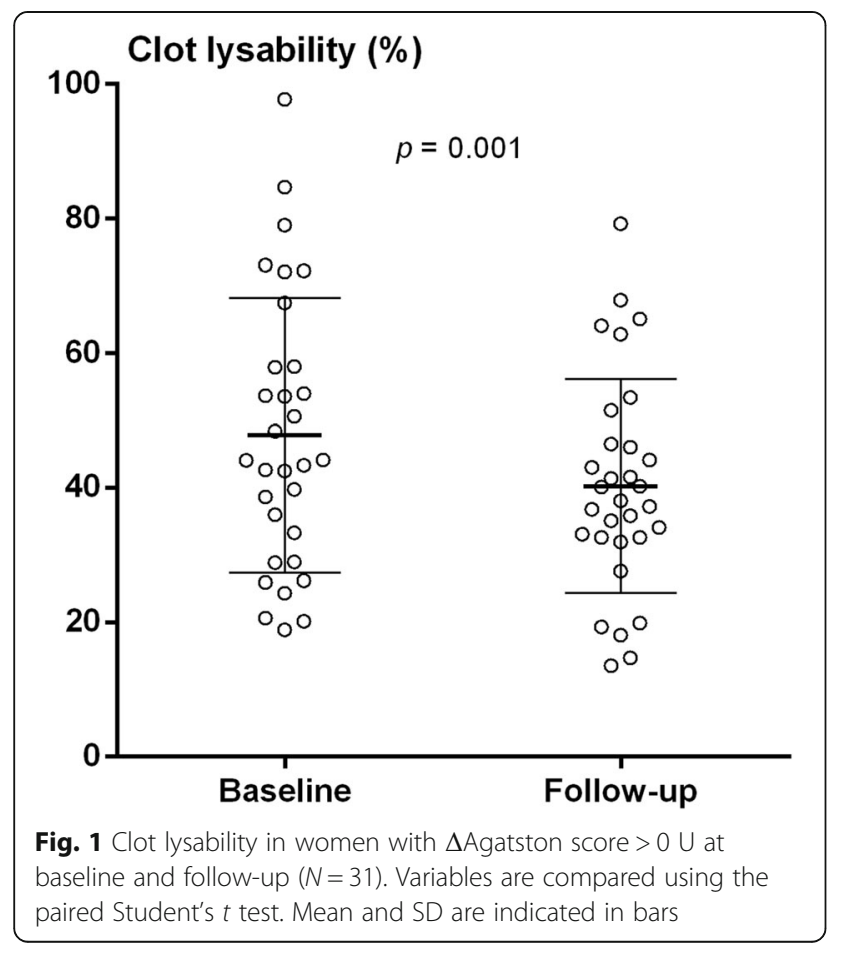

\section{Discussion}

In the present prospective cross-sectional cohort study, comprising apparently healthy middle-aged individuals, we demonstrate significantly reduced fibrin clot lysability during a 5-year follow-up in women with progression of

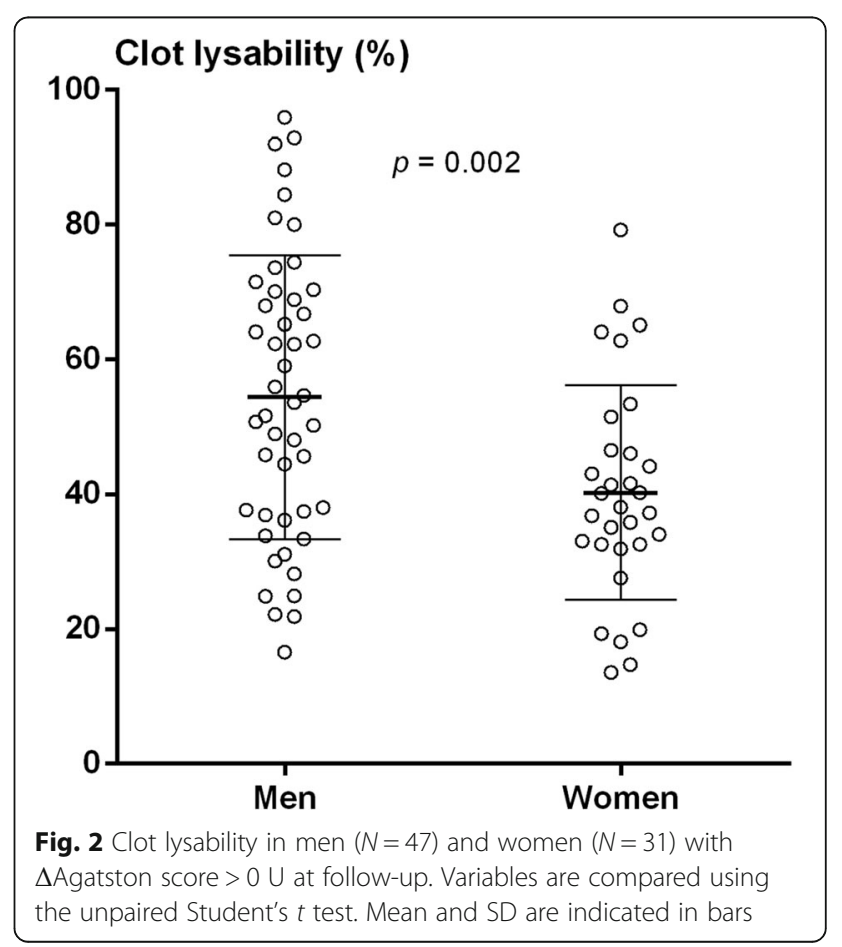




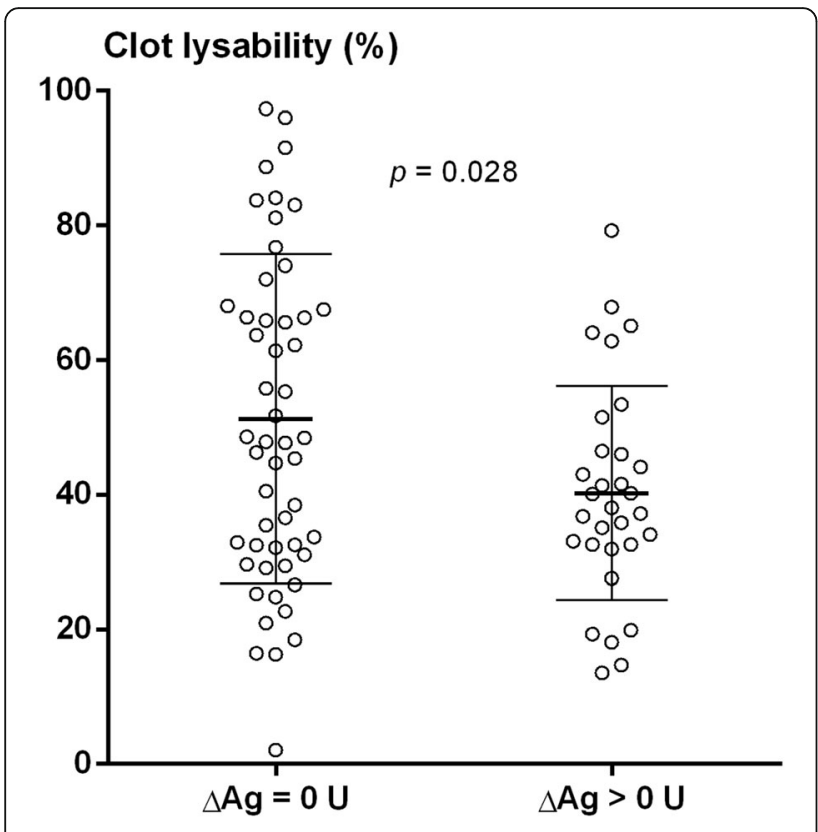

Fig. 3 Clot lysability in women with $\Delta$ Agatston score $=0 \cup(N=53)$ and $\Delta$ Agatston score $>0 \cup(N=31)$ at follow-up. Variables are compared using the unpaired Student's $t$ test. Mean and SD are indicated in bars

CAC. Furthermore, women with progression of CAC had reduced clot lysability compared to men as well as compared to women without progression of CAC, as these subgroups had no significant alterations in clot lysability over time. These findings were independent of confounding covariates.

Although several hypotheses have been suggested as the potential cause for sex differences in the natural history of CVD, basic mechanisms are still unknown. In this perspective, a positive correlation between high fibrinogen levels in young adulthood and incidence of CAC later in life has been reported in the Coronary Artery Risk Development in Young Adults (CARDIA) study [13], and other studies have reported an association between high fibrinogen levels and thrombosis [26]. In general, women have higher plasma concentration of fibrinogen than agematched men [27], and fibrinogen as a precursor of fibrin is considered to be an important determinant of the fibrin structure [28]. A prothrombotic effect of increased fibrinogen is probably closely linked to alterations in fibrin structure $[29,30]$ causing fibrin to be more resistant to lysis. In the present study, we observed differences in fibrinogen concentrations between sexes at baseline but not at follow-up, and although the fibrinogen concentration correlated with clot lysability, the sex-related differences in clot lysability remained significant after adjustment for the potential confounding effect of fibrinogen. These findings indicate that other factors than fibrinogen are responsible for the observed differences in fibrin clot lysability.
We have previously shown that women with atrial fibrillation differ in fibrin polymerization characteristics compared to men [18] and that women receiving OC have alterations in fibrin structure and increased clot lysability [31]. Moreover, middle-aged women receiving estrogen therapy have a reduced burden of CAC compared to women receiving placebo [32]. We therefore hypothesize that the reduced wall repair mechanisms and increasing CAC observed in women after menopause [8] may partly be due to altered fibrin lysability. Thus, a reduction of more than $20 \%$ in fibrin clot lysability recorded in women with CAC progression may contribute to the different cardiovascular pathophysiology observed in women after the menopause.

In addition, clinical studies suggest that fibrinogen and fibrin deposits in atherosclerotic plaques, and not circulating fibrinogen, contribute to plaque growth and stability by stimulating migration and proliferation of smooth muscle cells as well as creating a matrix for the calcium deposits in the growing plaque [11-13]. As both fibrinogen and fibrin are present in early as well as advanced atherosclerotic plaques [33], a reduced fibrin clot lysability may play a central role in plaque growth and remodeling, with important influence in wound healing and vascular remodeling [34]. In the modern context of Virchow's triad [35], the present study might therefore be of interest, as we report a correlation between CAC as an abnormality in the vessel wall and a concomitant reduced clot lysability occurring only in women.

\section{Limitations}

Negative $\Delta \mathrm{Ag}$ was recorded in eight participants and was registered as $\Delta \mathrm{Ag}=0 \mathrm{U}$, and of these, five participants had a decrease in $\mathrm{Ag} \geq 10 \mathrm{U}$. However, repeat analysis after exclusion of all eight participants did not change our findings. Several studies report difficulties in assessing CAC progression and definition of subgroups based on progression in CAC [36-39]. Our subgroup analysis showed a trend towards decreased fibrin clot lysability with increasing $\Delta \mathrm{Ag}$ in women compared to men; however, the number of participants in each group is limited. Further research in a larger population is needed to perform subgroup analyses. The hormonal status in the women was unknown, but no significant differences in clot lysability between the two age cohorts in women at both baseline and follow-up were observed. At the study inclusion, women taking any kind of hormone replacement therapy were excluded. Scanners from different vendors were used to assess CAC at baseline and follow-up. However, according to Willemink et al., both the median relative difference of $\mathrm{Ag}$ and the reclassification rate between the Philips and Toshiba scanners used in the present study were low [40]. Fifty study participants were not re-examined at follow-up, 
and clinical information on these participants are not available. However, these participants were comparable to the study participants who were re-assessed in terms of cardiovascular risk factors and $\mathrm{Ag}$ at baseline.

\section{Conclusion}

Women with progression of CAC over 5 years have reduced clot lysability compared to men. In addition, these women have reduced clot lysability compared to women with no development of CAC. This study suggests that fibrin clot lysability plays a role in the evolution of CVD.

\begin{abstract}
Abbreviations
Ag: Agatston score; BMI: Body mass index; CAC: Coronary artery calcification; CAD: Coronary artery disease; CARDIA: Coronary Artery Risk Development in Young Adults study; CRP: C-reactive protein; CT: Computed tomography; CVD: Cardiovascular disease; HDL: High-density lipoprotein; IQR: Interquartile range; LDL: Low-density lipoprotein; MI: Myocardial infarction; OC: Oral contraceptives; SD: Standard deviation
\end{abstract}

\begin{abstract}
Acknowledgements
We express our gratitude to the study participants for their participation in the current study. We thank Anette Larsen and Kathrine Overgaard, Unit for Thrombosis Research, University of Southern Denmark, and the staff of the Department of Clinical Biochemistry, Hospital of South West Denmark, Esbjerg, for the skillful biochemical analysis. We are indebted to the dedicated staff at the Departments of Cardiology and Radiology, Hospital of South West Denmark, Esbjerg. The authors thank Pia V. Larsen, Department of Public Health, University of Southern Denmark, Odense, for valuable statistical assistance.
\end{abstract}

\section{Funding}

This work was supported by the Cardiac Research Fund, Hospital of South West Denmark, Esbjerg; Institute of Regional Health Research: Centre South West Jutland, Hospital of South West Denmark, Esbjerg; Institute of Regional Health Research, Faculty of Health Sciences, University of Southern Denmark; Edith and Vagn Hedegaard Jensen Foundation, Esbjerg, Denmark; and Karola Jørgensens Research Foundation, Esbjerg, Denmark. The sponsors only provided financial support for the conduct of the research and the preparation of the manuscript and had no influence in the study design, collection, analysis, and interpretation of data or in writing and submitting the present manuscript for publication.

\section{Availability of data and materials}

The datasets generated and analyzed during the current study are not available due to the individual privacy of the study participants. Datasets are available from the corresponding author on reasonable request.

\section{Authors' contributions \\ RR designed the study; collected, analyzed, and interpreted the data; and wrote the manuscript. NPRS, JJS, and JBG conceived and designed the study, analyzed and interpreted the data, contributed to the discussion, and reviewed the manuscript. Additionally, NPRS assisted in collecting and analyzing the cardiac $\subset T$ data, JJS was responsible for the biochemical analyses and helped review the figures and the statistics, and JBG was responsible for the biochemical analyses. BLN conceived and designed the study, contributed to the discussion, and reviewed the manuscript. All authors read and approved the final manuscript.}

\section{Ethics approval and consent to participate}

All procedures performed in the study were conducted in accordance with the ethical standards of the Regional Scientific Ethics Committee for Southern Denmark and with the ethical guidelines of the 1975 Declaration of Helsinki and its later amendments. The protocol was approved by the Regional Scientific Ethics Committee for Southern Denmark, reference number S20080140 and S20130169 (45023). Written informed consent for study participation and publication of study results were obtained from all individual participants included in the study.

\section{Competing interests}

Author Bjarne L. Nørgaard has received research grant from Siemens, Edwards Lifesciences and Heartflow. All other authors declare that they have no competing interests.

\section{Publisher's Note}

Springer Nature remains neutral with regard to jurisdictional claims in published maps and institutional affiliations.

\section{Author details}

${ }^{1}$ Department of Cardiology, Hospital of South West Denmark, Esbjerg, Denmark. ${ }^{2}$ Department of Regional Health Research, University of Southern Denmark, Esbjerg, Denmark. ${ }^{3}$ Department of Clinical Biochemistry, Hospital of South West Denmark, Esbjerg, Denmark. ${ }^{4}$ Unit for Thrombosis Research, Department of Regional Health Research, University of Southern Denmark, Esbjerg, Denmark. ${ }^{5}$ Department of Cardiology, Skejby University Hospital, Aarhus, Denmark.

Received: 8 December 2017 Accepted: 29 January 2018

Published online: 13 February 2018

\section{References}

1. Go AS, Mozaffarian D, Roger VL, Benjamin EJ, Berry JD, Blaha MJ, Dai S, Ford ES, Fox CS, Franco S, et al. Heart disease and stroke statistics-2014 update: a report from the American Heart Association. Circulation. 2014;129(3):e28-e292.

2. Daniels LB, Maisel AS. Cardiovascular biomarkers and sex: the case for women. Nat Rev Cardiol. 2015;12(10):588-96.

3. Merz AA, Cheng S. Sex differences in cardiovascular ageing. Heart. 2016; 102(11):825-31.

4. Kardys I, Vliegenthart R, Oudkerk M, Hofman A, Witteman JC. The female advantage in cardiovascular disease: do vascular beds contribute equally? Am J Epidemiol. 2007:166(4):403-12.

5. Jonsdottir LS, Sigfusson N, Gudnason V, Sigvaldason H, Thorgeirsson G. Do lipids, blood pressure, diabetes, and smoking confer equal risk of myocardia infarction in women as in men? The Reykjavik study. J Cardiovasc Risk. 2002; 9(2):67-76.

6. Pardhe BD, Ghimire S, Shakya J, Pathak S, Shakya S, Bhetwal A, Khanal PR, Parajuli NP. Elevated cardiovascular risks among postmenopausal women: a community based case control study from Nepal. Biochem Res Int. 2017; 2017:3824903.

7. Lerner DJ, Kannel WB. Patterns of coronary heart disease morbidity and mortality in the sexes: a 26-year follow-up of the Framingham population. Am Heart J. 1986:111(2):383-90.

8. Vitale C, Mendelsohn ME, Rosano GM. Gender differences in the cardiovascular effect of sex hormones. Nat Rev Cardiol. 2009:6(8):532-42.

9. Vaccarino V, Parsons L, Every NR, Barron HV, Krumholz HM. Sex-based differences in early mortality after myocardial infarction. National Registry of Myocardial Infarction 2 Participants. N Engl J Med. 1999;341(4):217-25.

10. Hvelplund A, Galatius S, Madsen M, Rasmussen JN, Rasmussen S, Madsen JK, Sand NP, Tilsted HH, Thayssen P, Sindby E, et al. Women with acute coronary syndrome are less invasively examined and subsequently less treated than men. Eur Heart J. 2010;31(6):684-90.

11. Smith EB. Fibrinogen, fibrin and fibrin degradation products in relation to atherosclerosis. Clin Haematol. 1986;15(2):355-70.

12. Borissoff Jl, Spronk HM, ten Cate H. The hemostatic system as a modulator of atherosclerosis. N Engl J Med. 2011;364(18):1746-60.

13. Green D, Chan C, Kang J, Liu K, Schreiner P, Jenny NS, Tracy RP. Longitudinal assessment of fibrinogen in relation to subclinical cardiovascular disease: the CARDIA study. J Thromb Haemost. 2010;8(3):489-95.

14. Fatah K, Silveira A, Tornvall P, Karpe F, Blomback M, Hamsten A. Proneness to formation of tight and rigid fibrin gel structures in men with myocardial infarction at a young age. Thromb Haemost. 1996;76(4):535-40.

15. Collet JP, Allali Y, Lesty C, Tanguy ML, Silvain J, Ankri A, Blanchet B, Dumaine $\mathrm{R}$, Gianetti J, Payot L, et al. Altered fibrin architecture is associated with hypofibrinolysis and premature coronary atherothrombosis. Arterioscler Thromb Vasc Biol. 2006;26(11):2567-73.

16. Schuett K, Savvaidis A, Maxeiner S, Lysaja K, Jankowski V, Schirmer SH, Dimkovic N, Boor P, Kaesler N, Dekker FW, et al. Clot structure: a potent mortality risk factor in patients on hemodialysis. J Am Soc Nephrol. 2017: 28(5):1622-30 
17. Skov J, Sidelmann JJ, Bladbjerg EM, Jespersen J, Gram J. Lysability of fibrin clots is a potential new determinant of stroke risk in atrial fibrillation. Thromb Res. 2014;134(3):717-22.

18. Gram J, Skov J, Bladbjerg EM, Sidelmann J, Jespersen J. Gender differences in fibrin polymerization and lysability of fibrin in patients with atrial fibrillation. J Stroke Cerebrovasc Dis. 2016;25(2):292-7.

19. Undas A, Szuldrzynski K, Stepien E, Zalewski J, Godlewski J, Tracz W, Pasowicz M, Zmudka K. Reduced clot permeability and susceptibility to lysis in patients with acute coronary syndrome: effects of inflammation and oxidative stress. Atherosclerosis. 2008;196(2):551-7.

20. Sjoland JA, Sidelmann JJ, Brabrand M, Pedersen RS, Pedersen JH, Esbensen K, Standeven KF, Ariens RA, Gram J. Fibrin clot structure in patients with end-stage renal disease. Thromb Haemost. 2007:98(2):339-45.

21. Collet JP, Mishal Z, Lesty C, Mirshahi M, Peyne J, Baumelou A, Bensman A, Soria J, Soria C. Abnormal fibrin clot architecture in nephrotic patients is related to hypofibrinolysis: influence of plasma biochemical modifications: a possible mechanism for the high thrombotic tendency? Thromb Haemost. 1999;82(5):1482-9.

22. Diederichsen AC, Sand NP, Norgaard B, Lambrechtsen J, Jensen JM, Munkholm $\mathrm{H}$, Aziz A, Gerke O, Egstrup K, Larsen ML, et al. Discrepancy between coronary artery calcium score and HeartScore in middle-aged Danes: the DanRisk study. Eur J Prev Cardiol. 2012;19(3):558-64.

23. Bjerrum IS, Sand NP, Poulsen MK, Nørgaard BL, Sidelmann JJ, Johansen A, Mickley $H$, Diederichsen AC. Non-invasive assessments reveal that more than half of randomly selected middle-aged individuals have evidence of subclinical atherosclerosis: a DanRisk substudy. Int J Cardiovasc Imaging. 2013;29(2):301-8. https://doi.org/10.1007/s10554-012-0091-8. Epub 2012 Jul 5.

24. Agatston AS, Janowitz WR, Hildner FJ, Zusmer NR, Viamonte M Jr, Detrano R. Quantification of coronary artery calcium using ultrafast computed tomography. J Am Coll Cardiol. 1990;15(4):827-32.

25. Gram AS, Bladbjerg EM, Skov J, Ploug T, Sjodin A, Rosenkilde M, Madsen DE, Stallknecht BM. Three months of strictly controlled daily endurance exercise reduces thrombin generation and fibrinolytic risk markers in younger moderately overweight men. Eur J Appl Physiol. 2015;115(6):1331-8.

26. de Moerloose P, Boehlen F, Neerman-Arbez M. Fibrinogen and the risk of thrombosis. Semin Thromb Hemost. 2010;36(1):7-17.

27. Vorster HH. Fibrinogen and women's health. Thromb Res. 1999:95(4):137-54.

28. Weisel JW, Litvinov RI. Fibrin formation, structure and properties. Subcell Biochem. 2017:82:405-56.

29. Kotze RC, Ariens RA, de Lange Z, Pieters M. CVD risk factors are related to plasma fibrin clot properties independent of total and or gamma fibrinogen concentration. Thromb Res. 2014;134(5):963-9.

30. Undas A, Ariens RA. Fibrin clot structure and function: a role in the pathophysiology of arterial and venous thromboembolic diseases. Arterioscler Thromb Vasc Biol. 2011;31(12):e88-99.

31. Sidelmann JJ, Kluft C, Krug AH, Winkler U, Jespersen J, Gram JB. Fibrin clot structure-pro-fibrinolytic effect of oral contraceptives in apparently healthy women. Thromb Haemost. 2017;117(4):700-5.

32. Manson JE, Allison MA, Rossouw JE, Carr JJ, Langer RD, Hsia J, Kuller LH, Cochrane BB, Hunt JR, Ludlam SE, et al. Estrogen therapy and coronaryartery calcification. N Engl J Med. 2007;356(25):2591-602.

33. Bini A, Fenoglio JJ Jr, Mesa-Tejada R, Kudryk B, Kaplan KL. Identification and distribution of fibrinogen, fibrin, and fibrin(ogen) degradation products in atherosclerosis. Use of monoclonal antibodies. Arteriosclerosis. 1989;9(1):109-21.

34. Ariens RA. Fibrin(ogen) and thrombotic disease. J Thromb Haemost. 2013; 11(Suppl 1):294-305

35. Watson T, Shantsila E, Lip GY. Mechanisms of thrombogenesis in atrial fibrillation: Virchow's triad revisited. Lancet. 2009;373(9658):155-66.

36. Budoff MJ, Hokanson JE, Nasir K, Shaw LJ, Kinney GL, Chow D, Demoss D, Nuguri V, Nabavi V, Ratakonda R, et al. Progression of coronary artery calcium predicts all-cause mortality. JACC Cardiovasc Imaging. 2010;3(12):1229-36.

37. Budoff MJ, Young R, Lopez VA, Kronmal RA, Nasir K, Blumenthal RS, Detrano RC, Bild DE, Guerci AD, Liu K, et al. Progression of coronary calcium and incident coronary heart disease events: MESA (Multi-Ethnic Study of Atherosclerosis). J Am Coll Cardiol. 2013;61(12):1231-9.

38. Radford NB, DeFina LF, Barlow CE, Lakoski SG, Leonard D, Paixao AR, Khera A, Levine BD. Progression of CAC score and risk of incident CVD. JACC Cardiovasc Imaging. 2016;9(12):1420-9.
39. McEvoy JW, Blaha MJ, Defilippis AP, Budoff MJ, Nasir K, Blumenthal RS, Jones SR. Coronary artery calcium progression: an important clinical measurement? A review of published reports. J Am Coll Cardiol. 2010; 56(20):1613-22.

40. Willemink MJ, Vliegenthart R, Takx RA, Leiner T, Budde RP, Bleys RL, Das M, Wildberger JE, Prokop M, Buls N, et al. Coronary artery calcification scoring with state-of-the-art CT scanners from different vendors has substantial effect on risk classification. Radiology. 2014;273(3):695-702.

\section{Submit your next manuscript to BioMed Central and we will help you at every step:}

- We accept pre-submission inquiries

- Our selector tool helps you to find the most relevant journal

- We provide round the clock customer support

- Convenient online submission

- Thorough peer review

- Inclusion in PubMed and all major indexing services

- Maximum visibility for your research

Submit your manuscript at www.biomedcentral.com/submit
Biomed Central 